\title{
Growth Rate and Trend Analysis of Wheat Crop in Uttar Pradesh, India
}

\author{
Manvendra Singh ${ }^{1}$ and K. Supriya ${ }^{1}$ \\ Department of Statistics and Mathematics, College of Agriculture, \\ ANGRAU, Rajendranagar, Hyderabad, India \\ *Corresponding author
}

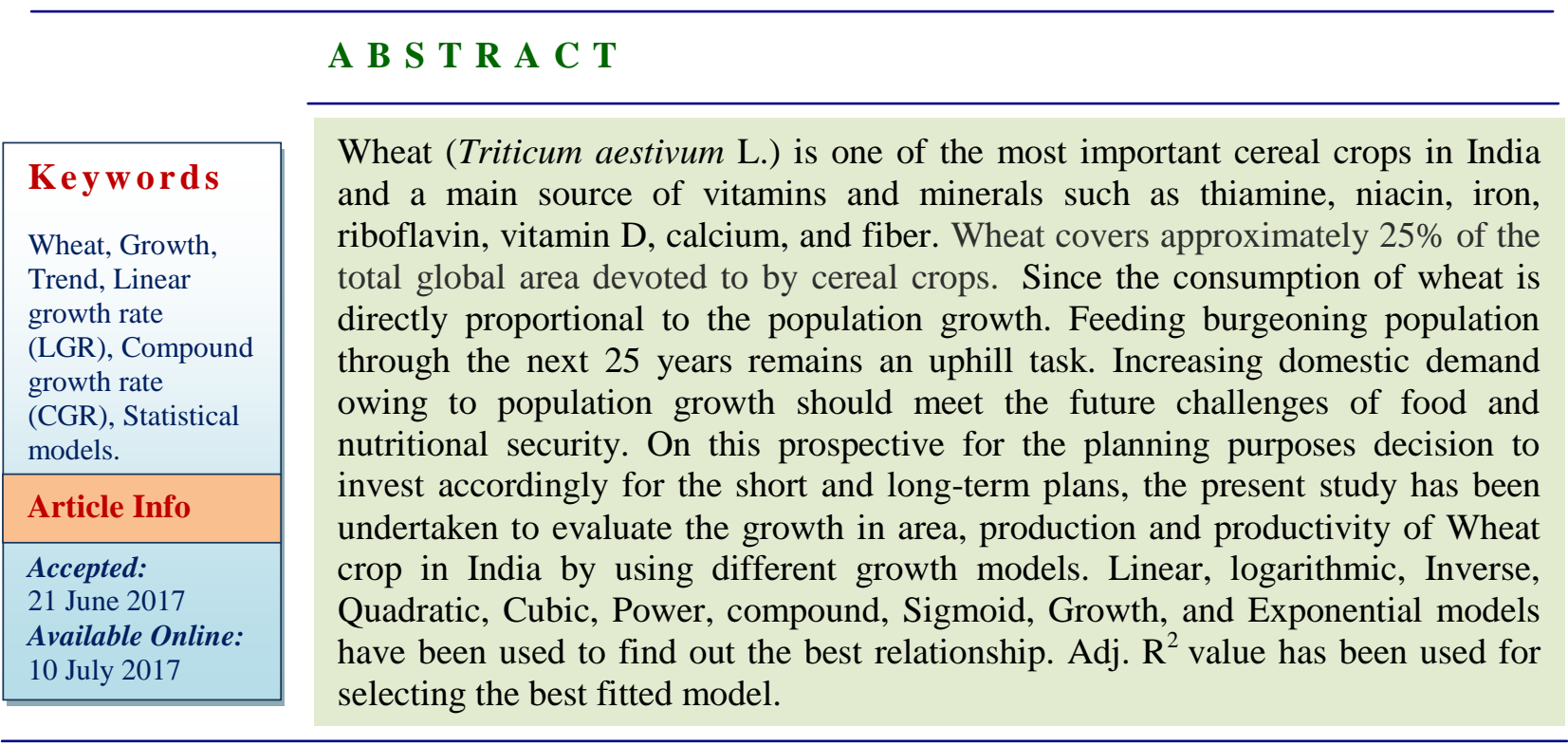

\section{Introduction}

Wheat (Triticum aestivum L.) is an important cereal crop in the world under a varied range of climatic conditions. In India, Wheat is grown from $11^{\circ} \mathrm{N}$ to $30^{\circ} \mathrm{N}$ latitude and from sea level up to elevation of $3658 \mathrm{~m}$ in the Himalayas. It is grown in a wide range of temperature and annual rainfall, from sandy loam soil to heavy black cotton clay soils (Chatterji, 1966).

Wheat is the excellent source of carbohydrates, energy and has no fat. It is also a good source of vitamins and minerals such as thiamine, niacin, iron, riboflavin, vitamin $\mathrm{D}$, calcium, and fiber. In India Wheat is cultivated under wide range of agro-climatic conditions from Kashmir and other mountainous region as well as wet soils in the deltaic coastal areas to arid soils in Rajasthan. It is also grown in the coastal sandy regions in some of the hilly tracts of north. The pace of wheat production has to be maintained accordingly due to fast increasing population of the country (Singh et al., 2003). Over 3000 varieties are under cultivation in different parts of the country and these varieties differ in their duration, grain quality and other plant characters viz., water requirement, response to fertilizers, resistance to diseases, drought, alkalinity and salinity etc. the cultivation 
practices adopted in different part of the country differs as per the agro climatic zones.

India occupies $2^{\text {nd }}$ position in the World Wheat production. In India, Wheat was grown all over the country with an area of 30 million hectares, production of 93.2 million tones and with the productivity of $2980 \mathrm{~kg} / \mathrm{ha}$ during 2010-11(Anonymous, 2013).

Keeping in view of the above discussion, the present study has been undertaken to evaluate the growth in area, production and productivity of Wheat crop in India by using different growth models.

Yoginder et al., (1980) aimed at studying the growth rates of crops for the periods of green revolution (period I: 1960-61 to 1969-70) and post-green revolution (period II: 1970-71 to 1978-79).

Singh et al., (1997) studied the trend in area, production and yield of wheat at the state level in India and the factors responsible for determining yield and acreage of important food grain crops. This study has been undertaken to throw light on the policy decision to invest accordingly for the short and long-term plans and also to provide a direction of research which would bring sustainable development in agriculture.

\section{Materials and Methods}

The time series secondary data of area, production and productivity of selected of wheat crop in India at in million hectare, million ton, kilogram/hectare from 1971 to 2010 are extracted from the from the publications of Centre for Monitoring Indian Economy (CMIE),Mumbai.( FigS. 1-3).

\section{Estimation of growth rate}

Linear growth rate (LGR) and compound growth rate (CGR) were used for the estimation of growth rates in crop characteristics i.e., area, production and productivity of Wheat crop in India.

\section{Linear function}

Linear function is given by the equation: $\mathrm{Y}=$ $a+b t$

Where,

$\mathrm{t}$ is the time in years, independent variable $\mathrm{Y}$ is the trend value of the dependent variable $\mathrm{a}$ and $\mathrm{b}$ are constants

The above equation is fitted by using the least squares method of estimation.

The linear growth rate is calculated by the formula:

Linear growth rate $\left(\right.$ LGR \%) $=\underset{\mathrm{y}}{\frac{\mathrm{b}}{=}} \times 100$

\section{Compound function}

Compound function is given by the equation: $\mathrm{Y}=\mathrm{a} \mathrm{b}^{\mathrm{t}}$

or $\quad \log \mathrm{y}=\log \mathrm{a}+\mathrm{t} \log \mathrm{b}$

Where,

$t$ is the time in years, independent variable

$\mathrm{y}$ is the characteristic (area, production or productivity of dependent variable)

$a$ and $b$ are parameters

The ' $a$ ' and ' $b$ ' are calculated by applying the method of Least Squares.

The compound growth rate: CGR $(\%)=(b-1)$ x 100

\section{Fitting the trend equations}

The trend equations were fitted by using different growth models.

Growth models are nothing but the models that describe the behavior of a variable overtime. Linear, logarithmic, Inverse, 
Quadratic, Cubic, Power, Sigmoid, Growth, and Exponential models have been used in the present study.

\section{Results and Discussion}

The linear growth rates and compound growth rates for the study period of 1971 to 2010 were estimated by fitting the linear function and compound function to the area, production and productivity of Wheat crop, respectively. The models fitted to the time series data of area, production and productivity were linear, logarithmic, inverse, quadratic, cubic, compound, S-curve, growth, power and exponential.

Growth rates in area, production and productivity of wheat crop in Uttar Pradesh

\section{Growth rates in area}

It was found that, in Uttar Pradesh average area under Wheat during the study period (1971-2010) was 24.22 million hectares. The coefficient of variation recorded for the study period was 13.40per cent and the linear and compound growth rates recorded during study period were 1.00 and 1.07 per cent per annum respectively(Table 2). The area of wheat in Uttar Pradesh exhibited a positive trend and it was found significant at $1 \%$ level of significance.

\section{Growth rates in production}

In Uttar Pradesh the average production during the study period (1971-2010) was 54.02 thousand tones with coefficient of variation 10.84. Linear and compound growth rates were 1.67 and 1.70 per cent per annum respectively. The production of wheat in India exhibited a positive trend and it was significant at $1 \%$ level of significance (Table 2).

\section{Growth rates in productivity}

Regarding the productivity of wheat in Uttar Pradesh during the study period (1971-2010) was $2159.67 \mathrm{~kg} / \mathrm{hectare}$. Productivity of Uttar Pradesh showed a coefficient of variation 27.99 per cent. Linear and Compound growth rate observed were 2.48 and 2.66 per cent respectively. The productivity growth rates of wheat in India exhibit positive trend and it was also significant at $1 \%$ level of significance (Table 2).

As a whole, the growth rates of productivity were higher than area and production.

Fitting of different growth models to area, production and productivity wheat of crop in Uttar Pradesh

\section{Fitting of different growth models to area}

Area of Wheat in Uttar Pradesh showed a constant growth pattern in the study period of 1971 to 2010 . The results obtained by fitting all the ten growth models were presented in Table 3.Adj $\mathrm{R}^{2}$ values for all the models were 0.895 for linear function, 0.893 for logarithmic function, 0.405 for inverse function, 0.902 for quadratic function, 0.911 for cubic function, 0.875 for compound function, 0.858 for power function, 0.438 for S- curve, 0.873 for growth function, and 0.873 for exponential function, respectively. All the models Adj $\mathrm{R}^{2}$ values were significant at $1 \%$ level of significance. Cubic model was found to be the best for estimation of area of wheat in India with higher $\operatorname{AdjR}^{2}$ value 0.911.

\section{Fitting of different growth models to production}

The Production of Wheat in India showed a systematic growth pattern during the study period of 1971 to 2010. The results obtained by fitting all the ten growth models were 
presented in Table 4.Adj $\mathrm{R}^{2}$ values among all the models were 0.962 for linear function, 0.819 for logarithmic function, 0.332 for inverse function, 0.966 for quadratic function, 0.966 for cubic function, 0.925 for compound function, 0.888 for power function, 0.411 for S- curve, 0.925 for growth function, and 0.925 for exponential function, respectively. In all the models, $\operatorname{Adj} R^{2}$ values were significant at $1 \%$ level of significance. Cubic model was found to be the best for estimation of area of wheat in India with higher $\operatorname{Adj}^{2}$ value 0.966 .

Fitting of different growth models to productivity

The Productivity of Wheat in India showed an increasing trend during the study period of 1971 to 2010 . The results obtained by fitting all the ten growth models were presented in Table 5. Adj $\mathrm{R}^{2}$ values for all the models were 0.944 for linear function, 0.834 for logarithmic function, 0.342 for inverse function, 0.964 for quadratic function, 0.969 for cubic function, 0.914 for compound function, 0.869 for power function, 0.384 for S- curve, 0.914 for growth function, and 0.914 for exponential function, respectively.

In all the models, Adj $\mathrm{R}^{2}$ values were significant at $1 \%$ level of significance. Cubic model was found to be the best for estimation of area of wheat in India with higher $\operatorname{Adj} R^{2}$ value 0.969 .

Table.1 Expressions of model

\begin{tabular}{|l|l|l|}
\hline Sl.No. & Model & Expression \\
\hline $\mathbf{1}$ & Linear & $y=b_{0}+b_{1} x$ \\
\hline $\mathbf{2}$ & Logarithmic & $y=b_{0}+b_{1} \ln (x)$ \\
\hline $\mathbf{3}$ & Inverse & $y=b_{0}+\frac{b_{1}}{x}$ \\
\hline $\mathbf{4}$ & Quadratic & $y=b_{0}+b_{1} x+b_{2} x^{2}$ \\
\hline $\mathbf{5}$ & Cubic & $y=b_{0}+b_{1} x+b_{2} x^{2}+b_{3} x^{3}$ \\
\hline $\mathbf{6}$ & Compound & $y=b_{0} b_{1}^{\alpha^{2}}$ \\
\hline $\mathbf{7}$ & Power & $y=b_{0} x^{b_{1}}$ \\
\hline $\mathbf{8}$ & Sigmoid (S) & $y=\exp ^{b_{0}+\frac{o_{1}}{x}}$ \\
\hline $\mathbf{9}$ & Growth & $y=\exp ^{b_{0}+b_{1} x}$ \\
\hline $\mathbf{1 0}$ & Exponential & $y=b_{0} \exp ^{b_{1} x}$ \\
\hline
\end{tabular}

Table.2 LGR and CGR of Uttar Pradesh in respect to area (m ha), production $(\mathrm{m} \mathrm{t})$ and productivity ( $\mathrm{kg} / \mathrm{ha})$

\begin{tabular}{|l|c|c|c|}
\hline \multirow{2}{*}{$\begin{array}{l}\text { Growth Rate } \\
(\%)\end{array}$} & \multicolumn{3}{|c|}{ Uttar Pradesh } \\
\cline { 2 - 4 } & Area (m ha) & Production(m t) & Productivity(kg/ha) \\
\hline LGR (\%) & $1.00^{* *}$ & $1.67^{* *}$ & $2.48^{* *}$ \\
\hline CGR (\%) & $1.07^{* *}$ & $1.70^{* *}$ & $2.66^{* *}$ \\
\hline CV (\%) & 13.40 & 10.84 & 27.99 \\
\hline
\end{tabular}


Table.3 Growth models for the area of wheat in India

\begin{tabular}{|l|l|l|l|l|l|l|}
\hline Model & $\boldsymbol{b}_{\mathbf{0}}$ & $\boldsymbol{b}_{\mathbf{1}}$ & $\boldsymbol{b}_{\mathbf{2}}$ & $\boldsymbol{b}_{\mathbf{3}}$ & $\mathbf{A d j R}^{2}$ & RMSE \\
\hline Linear & 19510.88 & 229.74 & & & $0.895^{* *}$ & 864.33 \\
\hline Logarithmic & 16007.83 & 2977.75 & & & $0.893^{* *}$ & 1325.52 \\
\hline Inverse & 25360.34 & -10656.13 & & & $0.405^{* *}$ & 4793.29 \\
\hline Quadratic & 18775.49 & 334.79 & -2.56 & & $0.902^{* *}$ & 787.06 \\
\hline Cubic & 17892.16 & 578.42 & -17.24 & 0.24 & $0.911^{* *}$ & 717.20 \\
\hline Compound & 19709.30 & 1.01 & & & $0.875^{* *}$ & 971.46 \\
\hline Power & 16855.32 & 0.13 & & & $0.858^{* *}$ & 1089.09 \\
\hline S- curve & 10.14 & -0.47 & & & $0.438^{* *}$ & 4435.12 \\
\hline Growth & 9.89 & 0.01 & & & $0.873^{* *}$ & 971.46 \\
\hline Exponential & 19709.30 & 0.01 & & & $0.873^{* *}$ & 971.46 \\
\hline
\end{tabular}

Table.4 Growth models for production of wheat in India

\begin{tabular}{|l|l|l|l|l|l|l|}
\hline Model & $\boldsymbol{b}_{\mathbf{0}}$ & $\boldsymbol{b}_{\mathbf{1}}$ & $\boldsymbol{b}_{\mathbf{2}}$ & $\boldsymbol{b}_{\mathbf{3}}$ & $\mathbf{A d j R}^{2}$ & $\mathbf{R M S E}$ \\
\hline Linear & 21639.123 & 1579.416 & & & $0.962^{* *}$ & 1335.44 \\
\hline Logarithmic & 95.795 & 19550.778 & & & $0.819^{* *}$ & 6400.30 \\
\hline Inverse & 60903.874 & -64383.802 & & & $0.332^{* *}$ & 23642.55 \\
\hline Quadratic & 18611.058 & 2011.997 & -10.551 & & $0.966^{* *}$ & 1200.92 \\
\hline Cubic & 20408.445 & 1516.275 & 19.306 & -0.485 & $0.966^{* *}$ & 1196.30 \\
\hline Compound & 25981.997 & 1.033 & & & $0.925^{* *}$ & 35.40 \\
\hline Power & 15634.555 & 0.425 & & & $0.888^{* *}$ & 28.68 \\
\hline S- curve & 10.987 & -1.485 & & & $0.411^{* *}$ & 208.04 \\
\hline Growth & 10.165 & 0.032 & & & $0.925^{* *}$ & 35.40 \\
\hline Exponential & 25981.997 & 0.032 & & & $0.925^{* *}$ & 35.40 \\
\hline
\end{tabular}

Table.5 Growth models for productivity of wheat in India

\begin{tabular}{|l|l|l|l|l|l|l|}
\hline Model & $\boldsymbol{b}_{\mathbf{0}}$ & $\boldsymbol{b}_{\mathbf{1}}$ & $\boldsymbol{b}_{\mathbf{2}}$ & $\boldsymbol{b}_{\mathbf{3}}$ & $\mathbf{A d j R}^{\mathbf{2}}$ & $\mathbf{R M S E}$ \\
\hline Linear & 1232.803 & 45.766 & & & $0.944^{* *}$ & 169.90 \\
\hline Logarithmic & 579.670 & 576.983 & & & $0.834^{* *}$ & 501.40 \\
\hline Inverse & 2375.091 & -1908.041 & & & $0.342^{* *}$ & 1993.88 \\
\hline Quadratic & 1044.012 & 72.736 & -0.658 & & $0.964^{* *}$ & 108.17 \\
\hline Cubic & 1165.890 & 39.122 & 1.367 & $-3.292 \mathrm{E}-02$ & $0.969^{* *}$ & 93.71 \\
\hline Compound & 1318.261 & 1.023 & & & $0.914^{* *}$ & 334.82 \\
\hline Power & 927.574 & .296 & & & $0.869^{* *}$ & 276.48 \\
\hline S- curve & 7.756 & -1.012 & & & $0.384^{* *}$ & 1777.59 \\
\hline Growth & 7.184 & .023 & & & $0.914^{* *}$ & 334.82 \\
\hline Exponential & 1318.261 & .023 & & & $0.914^{* *}$ & 334.82 \\
\hline
\end{tabular}


Fig.1 Time series data of total wheat cultivated area (million hectare) of Uttar Pradesh from 1971 to 2010

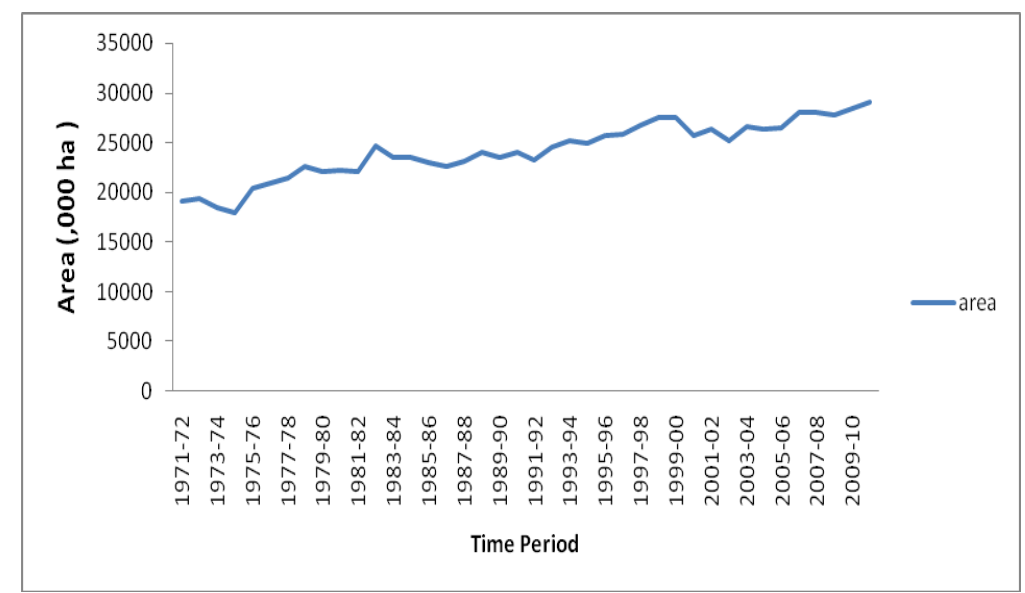

Fig.2 Time series data of total wheat production (million ton) of Uttar Pradesh from 1971 to 2010

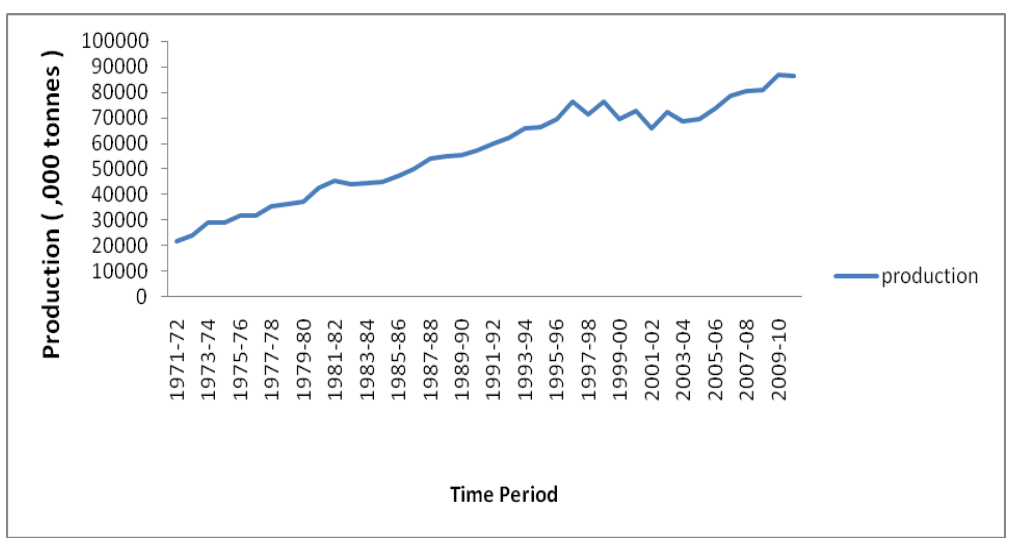

Fig.3 Time series data of total wheat productivity (Kg/ha) of Uttar Pradesh from 1971 to 2010

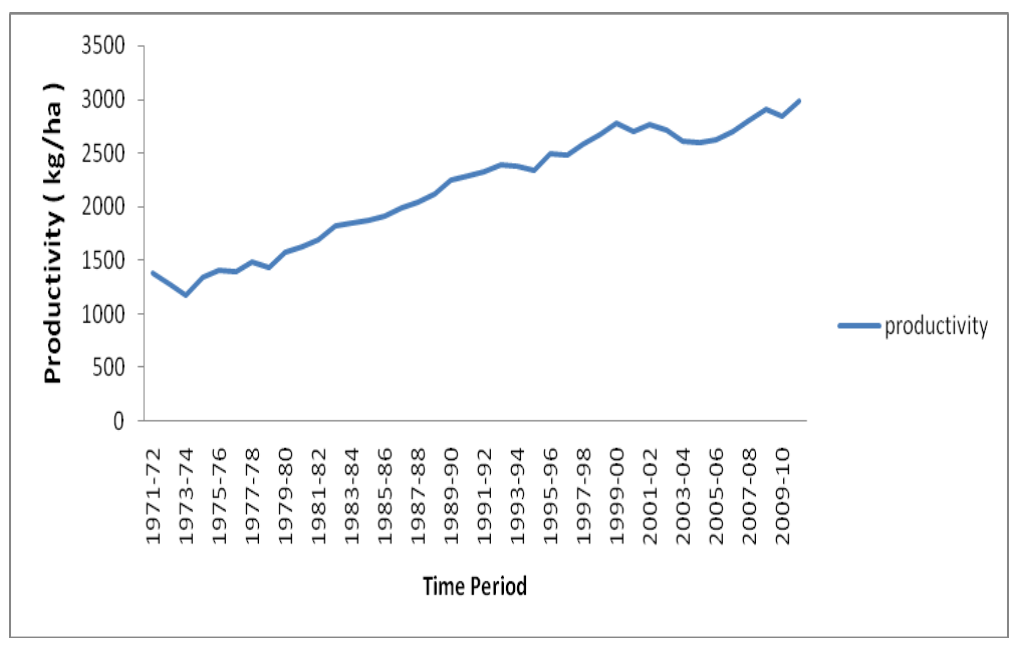


In conclusion, the present investigation has been undertaken to evaluate the growth in area, production and productivity of Wheat crop in Uttar Pradesh. The linear growth rates and compound growth rates for the study period of 1971 to 2010 were estimated by fitting the linear function and compound function to the area, production and productivity of Wheat crop, respectively. The average area, production and productivity under Wheat in Uttar Pradesh during the study period were 9.6 million hectares, 30.01 million tonnes and $3113.00 \mathrm{~kg} / \mathrm{ha}$ respectively and exhibited significantly increasing trend with the linear and compound growth rates of 1.00 and 1.07 per cent, respectively for area and for the production it was 1.67 and 1.70 per cent, respectively. However, the productivity of Wheat exhibited a positive trend with the linear and compound growth rates of 2.48 and 2.66 per cent, respectively. Among the area, production and productivity in Uttar Pradesh, the production exhibited higher growth rates with an increasing trend due to increased trend in growth rates of area and productivity. Among the area, production and productivity, the productivity exhibited higher growth rates with an increasing trend due to increased trend in growth rates of area and productivity. On the basis of the $\operatorname{Adj}^{2}$ values, cubic model was found to be the best for estimation of area, production and productivity of wheat in India.

\section{References}

Anonymous. 2013. publications of Centre for Monitoring Indian Economy (CMIE), Mumbai, India.

Chatterji, A. 1966. A study of agricultural rates during 1950-60 in India. Indian J. Agri. Economics, 20: 20-32.

Singh, R.P. 2003. Analysis of growth performance of wheat crop in Jharkhand; J. Res. Birsa Agri. Univ., 15(2): 217-223.

Yoginder Alagh, K. and Sharma, P.S. 1980. Growth rates of crop production 1960-61 to 1978-79 is it decelerating? Indian J. Agri. Economics, 35(2): 104-118.

Singh, I.J., Karwasra, K.N. and Rai, J.C. 1997. Regional variations in agricultural performance in India. Indian J. Agri. Economics, 52(3): 374-386.

\section{How to cite this article:}

Manvendra Singh and K. Supriya. 2017. Growth Rate and Trend Analysis of Wheat Crop in Uttar Pradesh. Int.J.Curr.Microbiol.App.Sci. 6(7): 2295-2301. doi: https://doi.org/10.20546/ijcmas.2017.607.270 